\title{
BMJ Open Aetiology and prognostic risk factors of mortality in patients with pneumonia receiving glucocorticoids alone or glucocorticoids and other immunosuppressants: a retrospective cohort study
}

\author{
Lijuan Li (D) , ${ }^{1}$ Steven H Hsu, ${ }^{2}$ Xiaoying Gu, ${ }^{1}$ Shan Jiang, ${ }^{1}$ Lianhan Shang, ${ }^{1}$ \\ Guolei Sun, ${ }^{1}$ Lingxiao Sun, ${ }^{1}$ Li Zhang, ${ }_{1}^{1}$ Chuan Wang, ${ }^{3}$ Yali Ren, ${ }^{4}$ Jinxiang Wang, ${ }^{5}$ \\ Jianliang Pan, ${ }^{6}$ Jiangbo Liu, ${ }^{7}$ Cao Bin ${ }^{8}$
}

To cite: Li L, Hsu SH, Gu X, et al. Aetiology and prognostic risk factors of mortality in patients with pneumonia receiving glucocorticoids alone or glucocorticoids and other immunosuppressants: a retrospective cohort study. BMJ Open 2020;10:e037419. doi:10.1136/ bmjopen-2020-037419

- Prepublication history for this paper is available online. To view these files, please visit the journal online (http://dx.doi org/10.1136/bmjopen-2020037419).

Received 04 February 2020 Revised 10 July 2020 Accepted 16 July 2020
Check for updates

(C) Author(s) (or their employer(s)) 2020. Re-use permitted under CC BY-NC. No commercial re-use. See rights and permissions. Published by BMJ.

For numbered affiliations see end of article.

Correspondence to

Dr Cao Bin;

caobin_ben@163.com

\section{ABSTRACT}

Objectives Long-term use of high-dose glucocorticoids can lead to severe immunosuppression and increased risk of treatment-resistant pneumonia and mortality. We investigated the aetiology and prognostic risk factors of mortality in hospitalised patients who developed pneumonia while receiving glucocorticoid therapy alone or glucocorticoid and other immunosuppressant therapies.

Design Retrospective cohort study.

Setting Six secondary and tertiary academic hospitals in China.

Participants Patients receiving glucocorticoids who were hospitalised with pneumonia between 1 January 2013 and 31 December 2019.

Main outcomes We analysed the prevalence of comorbidities, microbiology, antibiotic susceptibility patterns, 30-day and 90-day mortality and prognostic risk factors.

Results

Conclusions A total of 716 patients were included, with pneumonia pathogens identified in $69.8 \%$ of patients. Significant morbidities occurred, including respiratory failure $(50.8 \%)$, intensive care unit transfer $(40.8 \%)$ and mechanical ventilation (36\%), with a 90 -day mortality of $26.0 \%$. Diagnosis of pneumonia occurred within 6 months of glucocorticoid initiation for $69.7 \%$ of patients with Cytomegalovirus (CMV) pneumonia and $79.0 \%$ of patients with Pneumocystis jirovecii pneumonia (PCP). Pathogens, including Pneumocystis, CMV and multidrug-resistant bacteria, were identified more frequently in patients with persistent lymphocytopenia and high-dose glucocorticoid treatment $(\geq 30 \mathrm{mg} /$ day of prednisolone or equivalent within 30 days before admission). The 90 -day mortality was significantly lower for non-CMV viral pneumonias than for PCP $(p<0.05)$, with a similar mortality as CMV pneumonias ( $24.2 \%$ vs $38.1 \%$ vs $27.4 \%$, respectively). Cox regression analysis indicated several independent negative predictors for mortality in this patient population, including septic shock, respiratory failure, persistent
Strengths and limitations of this study

- This is the first large-scale investigation of the aetiologies and prognostic risk factors of pneumonia in patients using glucocorticoids.

- This study had several strengths, including a large sample size from multiple centres (six hospitals in China) and examinations of sputum or bronchoalveolar lavage samples in all patients.

- In this retrospective study, all patients with pneumonia did not undergo the full array of pathogen testing, and some pathogens were not identified until at least 48 hours after admission, increasing the probability of nosocomial infections.

lymphocytopenia, interstitial lung disease and high-dose glucocorticoid use.

Patients who developed pneumonia while receiving glucocorticoid therapy experienced high rates of opportunistic infections, with significant morbidity and mortality. These findings should be carefully considered when determining treatment strategies for this patient population.

\section{INTRODUCTION}

Long-term use of glucocorticoids at high doses may result in severe immunosuppression and serious infections. ${ }^{1}$ Pulmonary infections occur most commonly in this context and remain one of the leading causes of death in immunocompromised patients. ${ }^{1-4}$ Infections caused by opportunistic pathogens, including Cytomegalovirus (CMV), Pneumocystis jirovecii and Aspergillus, have been reported in immunocompromised patients receiving glucocorticoids. ${ }^{2-4}$ Mortality rates of up to $45 \%$ have been identified in patients 
with rheumatic diseases treated with long-term glucocorticoid therapy who develop pulmonary infections, with rates increasing to $93 \%$ for those requiring mechanical ventilation. ${ }^{1}$ The paucity of studies related to patients who develop pneumonia while receiving glucocorticoid therapy may lead to an underestimation of pneumonia prevalence and an overestimation of disease burden in this patient population. These assumptions may result in mismanagement, with excessive use of broad-spectrum antibiotics and treatment failure due to absence of therapeutic guidance based on pathogenic data. Given the significant morbidity and mortality associated with glucocorticoid-induced immunosuppression, our study aimed to identify the clinical characteristics, pathogenic aetiologies and prognostic risk factors of pneumonia in this population.

\section{METHODS}

\section{Study design and participants}

We retrospectively recruited patients with pneumonia who were hospitalised between 1 January 2013 and 31 December 2017 at six secondary and tertiary academic hospitals in China. Pneumonia diagnoses were based on the American Thoracic Society and Infectious Disease Society of America's guidelines. ${ }^{56}$ Pneumonia was defined as the presence of a new pulmonary infiltrate with infiltrative changes identified on chest radiography or CT imaging combined with one or more of the following clinical manifestations: (1) recent cough, sputum production or aggravation of respiratory symptoms, and emergence of purulent sputum with or without chest pain; (2) fever (defined as an axillary temperature of $\geq 37.3^{\circ} \mathrm{C}$ ) or hypothermia (defined as an axillary temperature $<36^{\circ} \mathrm{C}$ ); (3) clinical signs of pulmonary consolidation and/or presence of moist crackles; or (4) white cell count $>10 \times 10^{9} / \mathrm{L}$ or $<4 \times 10^{9} / \mathrm{L}$, with or without neutrophilic predominance. We identified patients with connective tissue diseases, nephrotic syndrome or chronic glomerulonephritis, idiopathic interstitial pneumonia, bronchial asthma, chronic obstructive pulmonary disease, or other causes for immunosuppressive therapy. Study patients were then selected based on the following inclusion criteria: (1) oral or intravenous glucocorticoid treatment ${ }^{48}$ before admission; (2) pneumonia diagnosis on admission or during hospitalisation; and (3) at least 16 years of age. The exclusion criteria were as follows: (1) diagnosis of non-infectious pulmonary diseases, including lung cancer, interstitial lung diseases without infection, pulmonary embolism, or heart failure; (2) inability to provide consent for procedures.

\section{Study quality control}

Key investigators, including clinicians, statisticians, microbiologists and radiologists, worked together to draft the protocol and to create a single formatted case report form (CRF) used by all centres. Before study initiation, all investigators from the six centres received training related to the study protocol, including the screening process, definitions of underlying diseases and the formatted CRF. After data were collected, CRFs were reviewed by a trained researcher to ensure completeness and data quality.

The following data were collected from medical records of patients during their hospitalisations: (1) demographics; (2) clinical symptoms; (3) initial vital signs and lung examination findings; (4) severity of disease (indicated by intensive care unit (ICU) admission, use of invasive or non-invasive mechanical ventilation, pneumonia severity index (PSI) score and/or Confusion, uremia, elevated respiratory rate, hypotension, and aged 65 years or older (CURB-65 score) $)^{9-11}$; (5) laboratory and microbiological data (blood, sputum and/or bronchoalveolar lavage (BAL) samples, bacterial or fungal cultures, viral nucleic acid detection and antibiotic susceptibility patterns); (6) treatment information, including use of vasoactive agents, antimicrobials, glucocorticoids and/or other immunosuppressants; and (7) survival status 30 and 90 days after admission. High-dose steroid use was defined as equal to or greater than $30 \mathrm{mg} /$ day of prednisolone or an equivalent glucocorticoid within 30 days before admission. Persistent lymphocytopenia was defined as a peripheral blood lymphocyte count lower than $1 \times 10^{9} / \mathrm{L}$ for greater than 7 days.

\section{Data collection}

\section{Diagnostic procedures}

After identification of pulmonary infiltrates on chest imaging, BAL or sputum samples were obtained by treating physicians, and microorganisms were identified and tested for drug sensitivities. Bronchoscopic examinations were performed according to general guidelines. Lidocaine spray was applied to the upper airway and carina for local anaesthesia, and airways were thoroughly examined. BAL was performed by instilling $60-120 \mathrm{~mL}$ of a sterile saline solution two to four times into the distal bronchial tree, either at the affected lobe or in the middle lung lobe with more radiographic abnormalities. BAL specimens were aliquoted and immediately transported to laboratories. Bacterial cultures were incubated at $35^{\circ} \mathrm{C}$ in 5\%-10\% carbon dioxide for 48 hours. If Nocardia was suspected, the incubation time was prolonged. Fungal cultures were incubated at $27^{\circ} \mathrm{C}$ for 5 days under ambient conditions. Species were identified using matrix-assisted laser desorption/ionisation time-of-flight mass spectrometry (Brooks Instrument, Germany) or a BACTEC 9102 culture instrument (BD Biosciences, USA). Respiratory viral and atypical pathogens were detected by PCRs (Shanghai Zhijiang Biological Technology, China). The Platelia Aspergillus test was used for galactomannan detection (Bio-Rad Laboratories, Marnes-la-Coquette, France).

\section{Pathogen-specific diagnostic information}

We defined multidrug resistance (MDR) in specific organisms using the European Centre for Disease Prevention 


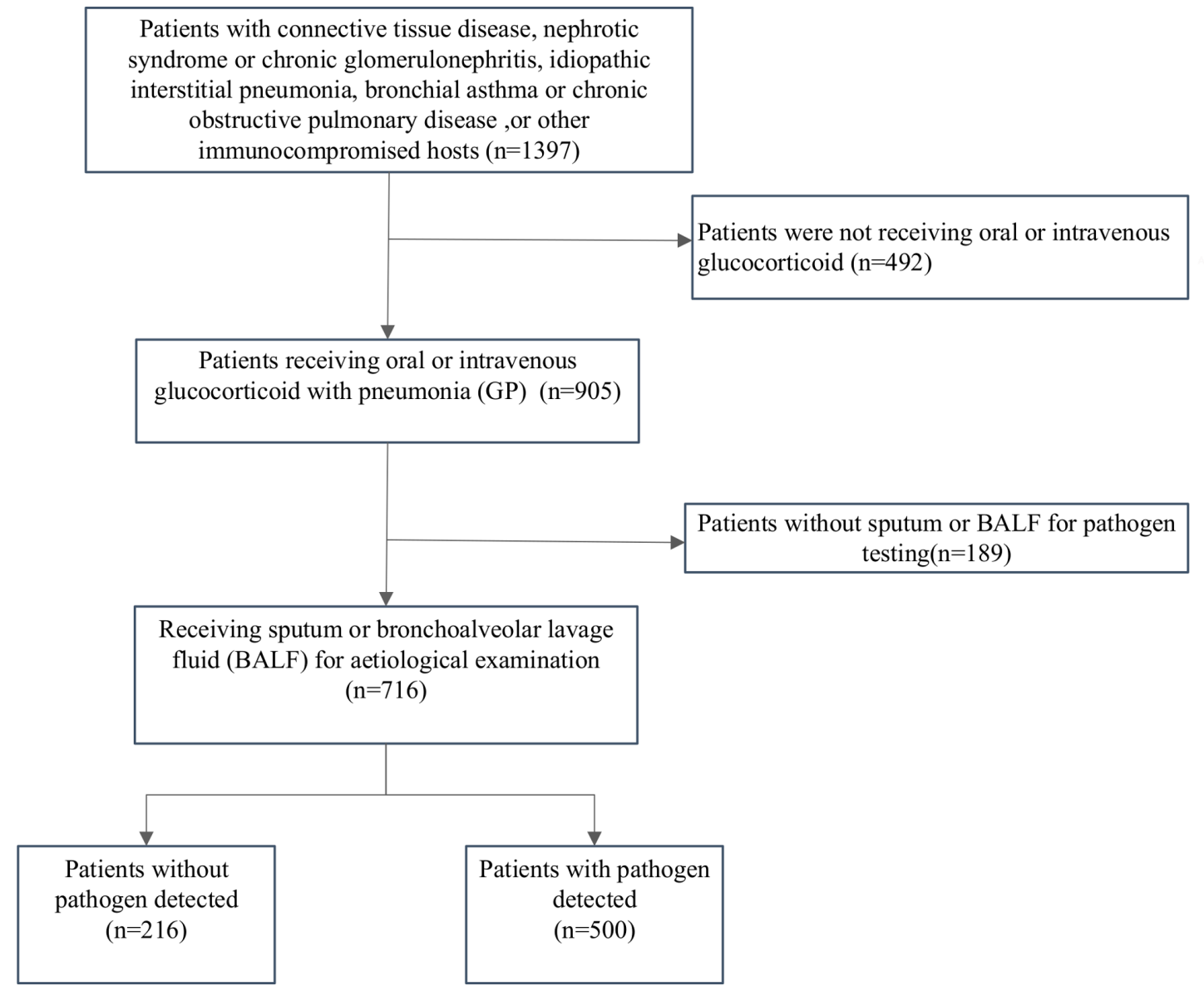

Figure 1 Study flow chart.

and Control and the Centers for Disease Control and Prevention criteria. We included the following species in this category: methicillin-resistant Staphylococcus aureus, vancomycin-resistant Enterococcus and Enterobacteriaceae producing extended-spectrum beta-lactamases. Pseudomonas aeruginosa, Acinetobacter baumannii and other nonfermenting Gram-negative bacilli were considered to be MDR pathogens if not susceptible to at least one agent in three or more antimicrobial categories. ${ }^{12} 13$

For diagnoses of pneumonias caused by atypical pathogens, including Legionella spp, Mycoplasma pneumoniae and Mycobacterium spp, we used PCR to identify bacterial DNA. Diagnoses of viral pneumonias were based on positive nucleic acid tests. For diagnosis of an Aspergillus pneumonia, one or more of the following criteria were required: (1) histopathologic or direct microscopic evidence of dichotomous septate hyphae with a positive culture for Aspergillus from tissue, (2) positive Aspergillus culture from BAL, (3) galactomannan optical index on $\mathrm{BAL} \geq 1$, (4) galactomannan optical index on serum $\geq 0.5$, or (5) Aspergillus sp identified by culture characteristics and microscopic morphology. ${ }^{1415}$

Diagnosis of Pneumocystis jirovecii pneumonia (PCP) required the following criteria: (1) high-resolution CT imaging showing diffuse ground-glass opacity with a patchy distribution and (2) microscopic examination of respiratory samples demonstrating Pneumocystis cystic or trophic forms or Pneumocystis DNA identified using PCR. ${ }^{16}$

\section{Statistical analysis}

Demographics, clinical characteristics and pathogen testing results were expressed as means $( \pm \mathrm{SD})$, medians (IQR) or numbers (percentage). Group comparisons were conducted using the Student's t-test or Wilcoxon rank-sum test for continuous variables with or without normal distributions, respectively. Categorical variables were compared between groups using the $\chi^{2}$ test. Histogram charts were used to depict glucocorticoid application timelines. Distributions for the duration of glucocorticoid use in patients with different respiratory pathogens were also compared using the $\chi^{2}$ test. Cox regression models were used to analyse the associations of septic shock, interstitial lung diseases, invasive and non-invasive mechanical ventilation, partial pressure of arterial oxygen and fraction of inspired oxygen ratio $\left(\mathrm{PaO}_{2} / \mathrm{FiO}_{2}\right)$ and persistent lymphocytopenia with 30-day and 90-day mortality. In the Cox analysis, adjustments were made for age, gender, noninvasive mechanical ventilation, invasive mechanical ventilation, respiratory failure, septic shock, ICU admission, high-dose corticosteroid use, persistent lymphocytopenia, interstitial lung disease, PSI score, CURB-65 score, PCP, and CMV and non-CMV viral infections. 
Table 1 Clinical characteristics of pneumonia between glucocorticoid users and those glucocorticoids with immunosuppressant users

\begin{tabular}{|c|c|c|c|c|}
\hline Variables & Total, $\mathrm{n}=716$ & $\begin{array}{l}\text { Glucocorticoid users, } \\
\mathrm{n}=297\end{array}$ & $\begin{array}{l}\text { Glucocorticoid with } \\
\text { immunosuppressant } \\
\text { users, } n=419\end{array}$ & $P$ value \\
\hline Sex, female, n (\%) & $341(47.6)$ & $123(41.4)$ & $218(52.0)$ & 0.005 \\
\hline Age, median (IQR) & $60(49,68)$ & $62.0(52.0,70.0)$ & $59.0(46.0,67.0)$ & $<0.001$ \\
\hline \multicolumn{5}{|l|}{ Symptoms and signs, $\mathrm{n}(\%)$} \\
\hline Fever & $534(74.6)$ & $225(75.8)$ & $309(73.7)$ & 0.543 \\
\hline Sputum production & $580(81.0)$ & $239(80.5)$ & $341(81.4)$ & 0.829 \\
\hline Dyspnoea & $431(60.2)$ & $185(62.3)$ & $246(58.7)$ & 0.335 \\
\hline Disturbance of consciousness & $40(5.6)$ & $11(3.7)$ & $29(6.9)$ & 0.065 \\
\hline \multicolumn{5}{|l|}{ Laboratory examination } \\
\hline White cell, $\times 10^{9} / \mathrm{L}$ (IQR) & $7.94(5.79,11.60)$ & $9.27(6.37,12.63)$ & $7.51(5.37,10.97)$ & $<0.001$ \\
\hline Mean haemoglobin $\pm S D(g / L)$ & $111.8 \pm 23.9$ & $113.1 \pm 24.2$ & $108.4 \pm 22.8$ & 0.034 \\
\hline Mean albumin $\pm S D(g / L)$ & $32.4 \pm 6.4$ & $33.3 \pm 6.2$ & $29.9 \pm 6.1$ & $<0.001$ \\
\hline Lactate dehydrogenase (U/L) & $328.5(227.8,506.0)$ & $338.0(226.0,528.0)$ & $312.0(228.5,495.0)$ & 0.525 \\
\hline Blood urea nitrogen (mmol/L) & $6.28(4.60,9.80)$ & $6.24(4.60,9.40)$ & $6.50(4.63,10.24)$ & 0.372 \\
\hline Serum creatinine (mmol/L) & $64.0(50.8,90.2)$ & $62.6(50.0,81.2)$ & $65.9(51.1,99.1)$ & 0.157 \\
\hline Procalcitonin (ng/mL) & $0.28(0.12,0.77)$ & $0.29(0.14,0.71)$ & $0.27(0.11,0.81)$ & 0.613 \\
\hline Oxygenation index & $241.4(126.6,347.6)$ & $228.0(128.1,351.2)$ & $243.1(122.4,347.6)$ & $<0.001$ \\
\hline Severe pneumonia index score & $76.5(59.3,101.0)$ & $77.0(60.0,103.0)$ & $76.0(57.0,100.0)$ & 0.845 \\
\hline CURB-65 score $>1$ & $211(29.5)$ & $88(29.6)$ & $123(1.0,2.0)$ & 0.937 \\
\hline Idiopathic interstitial pneumonia & $73(10.2)$ & $56(18.9)$ & $17(4.1)$ & $<0.001$ \\
\hline $\begin{array}{l}\text { Bronchial asthma or chronic } \\
\text { obstructive pulmonary disease }\end{array}$ & $30(4.2)$ & $30(10.1)$ & $0(0)$ & $<0.001$ \\
\hline Lymphoma & $17(2.4)$ & $8(2.7)$ & $9(2.1)$ & 0.628 \\
\hline $\begin{array}{l}\text { Bone marrow or haematopoietic } \\
\text { stem cell transplant }\end{array}$ & $7(1.0)$ & $1(0.3)$ & $6(1.4)$ & 0.144 \\
\hline Solid organ transplant & $63(8.8)$ & $0(0)$ & $63(15.0)$ & $<0.001$ \\
\hline Radiation pneumonitis & $8(1.1)$ & $7(2.4)$ & $1(0.2)$ & 0.008 \\
\hline Other immunocompromised hosts $\ddagger$ & $65(9.1)$ & $46(15.5)$ & $19(4.5)$ & $<0.001$ \\
\hline Bronchoalveolar lavage, n (\%) & $366(51.1)$ & $248(83.5)$ & $118(28.2)$ & $<0.001$ \\
\hline Total pathogenic positive rate & $500(69.8)$ & $218(73.4)$ & $282(67.3)$ & 0.080 \\
\hline \multicolumn{5}{|l|}{ Treatment, before admission, $\mathrm{n}(\%)$} \\
\hline High-dose steroids (>1 mg/kg/day) & $216(30.2)$ & $134(45.1)$ & $82(19.6)$ & $<0.001$ \\
\hline $\begin{array}{l}\text { Time of steroids use, median (IQR), } \\
\text { month }\end{array}$ & $4.0(2.0,18.0)$ & $3.0(1.6,9.0)$ & $6.0(2.0,24.0)$ & $<0.001$ \\
\hline $\begin{array}{l}\text { Accumulated dose of } \\
\text { glucocorticoids, methylprednisolone, } \\
g(\text { IQR) }\end{array}$ & $38(1.9,8.8)$ & $3.0(1.5,5.4)$ & $4.8(2.2,12.5)$ & $<0.001$ \\
\hline
\end{tabular}


Table 1 Continued

\begin{tabular}{|c|c|c|c|c|}
\hline Variables & Total, n=716 & $\begin{array}{l}\text { Glucocorticoid users, } \\
\mathrm{n}=297\end{array}$ & $\begin{array}{l}\text { Glucocorticoid with } \\
\text { immunosuppressant }^{\star} \\
\text { users, } n=419\end{array}$ & $P$ value \\
\hline Antibiotics & $502(70.1)$ & $219(73.7)$ & $283(67.5)$ & 0.074 \\
\hline Antiviral drugs & $113(15.8)$ & $44(14.8)$ & $69(16.5)$ & 0.550 \\
\hline \multicolumn{5}{|l|}{ Treatment, during hospitalisation, $\mathrm{n}(\%)$} \\
\hline $\begin{array}{l}\text { Anti-Pseudomonas aeruginosa } \\
\text { drugs }\end{array}$ & $547(76.4)$ & $220(74.1)$ & $327(78.0)$ & 0.218 \\
\hline Voriconazole or caspofungin & $282(39.4)$ & $105(35.4)$ & $177(42.2)$ & 0.063 \\
\hline Ganciclovir & $336(46.9)$ & $120(40.4)$ & $216(51.6)$ & 0.003 \\
\hline Trimethoprim & $333(46.5)$ & $111(37.4)$ & $222(53.0)$ & $<0.001$ \\
\hline \multicolumn{5}{|l|}{ Complications, n (\%) } \\
\hline Non-invasive ventilation & $173(24.2)$ & $63(21.2)$ & $110(26.3)$ & 0.121 \\
\hline ICU admission & $292(40.8)$ & $116(39.1)$ & $176(42.0)$ & 0.429 \\
\hline Septic shock during hospitalisation & $154(21.5)$ & $64(21.5)$ & $90(21.5)$ & 0.982 \\
\hline CAP & $635(88.7)$ & $263(88.6)$ & $372(88.8)$ & 0.924 \\
\hline $\begin{array}{l}\text { Extracorporeal membrane } \\
\text { oxygenation }\end{array}$ & $36(5.0)$ & $15(5.1)$ & $21(5.0)$ & 0.981 \\
\hline 30-day mortality & $162(22.6)$ & $66(22.2)$ & $96(22.9)$ & 0.828 \\
\hline 90-day mortality & $186(26.0)$ & $76(25.6)$ & $110(26.3)$ & 0.842 \\
\hline
\end{tabular}

*Other immunosuppressants: methotrexate, cyclosporine, cyclophosphamide, tacrolimus, sirolimus and azathioprine.

†Connective tissue disorders: rheumatoid arthritis, systemic lupus erythematosus, dermatomyositis, polymyositis, systemic sclerosis, Sjogren's syndrome, and so on. Immunosuppressive drugs: glucocorticoid, tacrolimus, sirolimus, cyclosporine, methotrexate, and so on. $\ddagger$ Other immunocompromised hosts: eczema, myelitis, autoimmune encephalitis, idiopathic thrombocytopenic purpura, and so on. CAP, community-acquired pneumonia; CURB-65, Confusion, uremia, elevated respiratory rate, hypotension, and aged 65 years or older; ICU, intensive care unit.

Statistical analyses were performed using SPSS V.19.0 (SPSS). All tests were two sided, and a $p$ value $<0.05$ was considered to indicate statistical significance.

\section{Patient and public involvement}

Neither patients nor the public were involved in the development of the research question, study design, patient recruitment, nor the conduct of the study.

\section{RESULTS}

In total, 1397 immunocompromised patients who developed pneumonia between 1 January 2013 and 31 December 2017 were identified. After excluding patients who were not receiving oral or intravenous glucocorticoids $(n=492)$ and those without sputum or BAL for pathogen testing $(n=189), 716$ patients with pneumonia who were receiving glucocorticoids were included in the final analysis (figure 1). Approximately $48 \%$ of study patients were female, with a median age of 60 . The main presenting symptoms included fever $(74.6 \%)$, cough $(87.7 \%)$ and dyspnoea (60.2\%). The most common underlying immune-related diseases were connective tissue diseases $(52.1 \%)$, interstitial lung disease (45.3\%), diabetes $(25 \%)$ and nephrotic syndrome or chronic glomerulonephritis (12.8\%). The average duration (IQR) of glucocorticoid use was $4(2,18)$ months. The positivity rate for pathogen testing was $69.8 \%(500 / 716)$. Among the $292(40.8 \%)$ patients who required ICU admission, $24.2 \%$ and $24 \%$ received non-invasive and invasive ventilation, respectively. The 30-day and 90-day mortality were $22.6 \%$ and $26.0 \%$, respectively. Complication rates were similar between patients using glucocorticoids alone and patients using glucocorticoids with other immunosuppressants (table 1 ).

MDR bacteria and CMV were more commonly identified in patients with hospital-acquired pneumonias (HAPs) than in those with community-acquired pneumonias (CAPs) $(p<0.05)$ (table 2). For CAPs, more pathogens were detected in patients with persistent lymphocytopenia than in patients without lymphocytopenia $(\mathrm{p}<0.05)$, including Pneumocystis, influenza A virus, CMV and MDR bacteria. Patients on high-dose corticosteroids developed pneumonia more frequently than those on low-dose corticosteroids in both the CAP and HAP groups, with more frequent identification of Klebsiella pneumoniae, MDR bacteria, Pneumocystis, CMV and Mycobacterium tuberculosis in patients on high-dose corticosteroids than in patients on low-dose corticosteroids in the CAP group $(\mathrm{p}<0.05)$. 


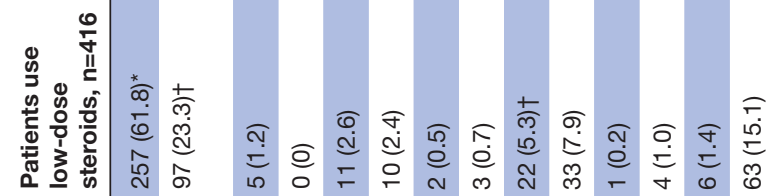

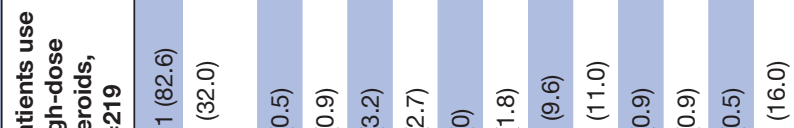

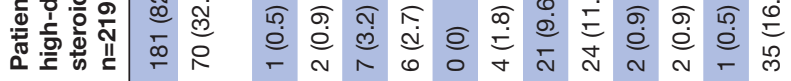

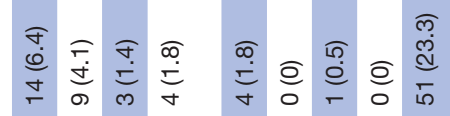

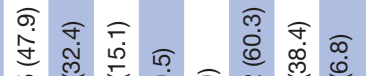

กุด ส ส

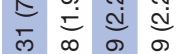

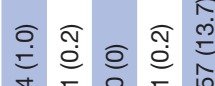

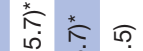

() $\frac{\pi}{2}$

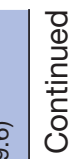

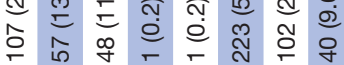
年

$\frac{\pi}{1}$

응

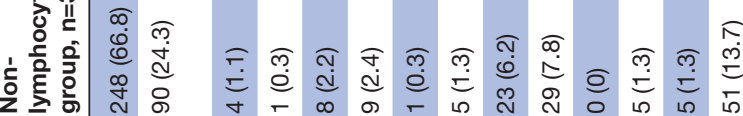

ฮุ

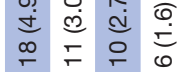

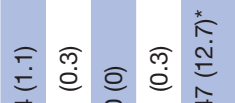

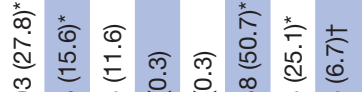

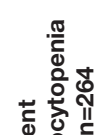

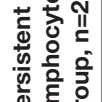

o

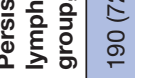

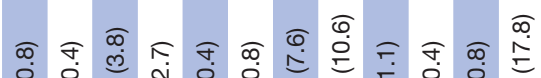

สู

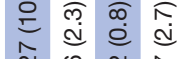

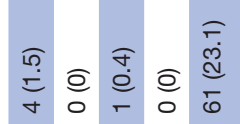

लำ

ल $\widehat{\text { ส }}$

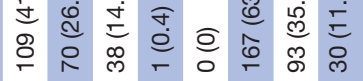

ชั

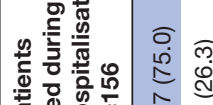

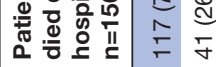

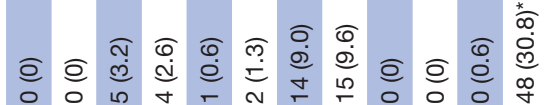

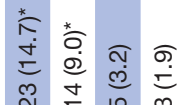

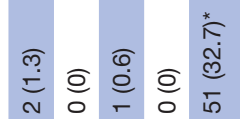

$\frac{\pi}{\operatorname{Ln}}+\frac{\pi}{0} \frac{\pi}{0}$

to $\widehat{0} \widehat{0}$

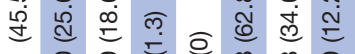

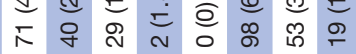

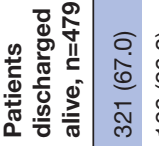

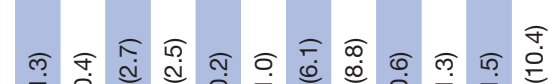

ब.

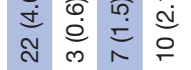

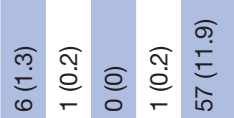

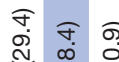

ก.

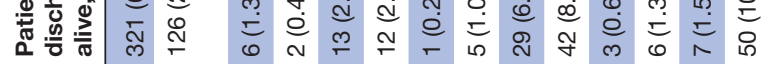

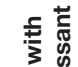

응 흔

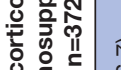

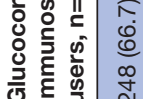

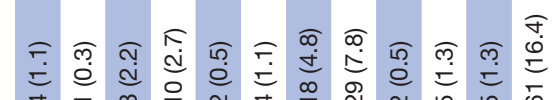

ल)

ล 을

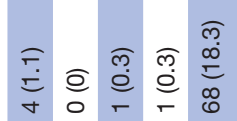

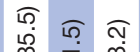

$\widehat{0} \bar{\infty}$

岁 m

\section{응 융}

음

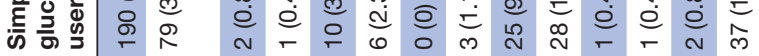

कo

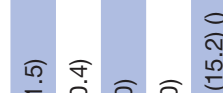

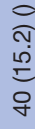

ชิ

○.

$\stackrel{5}{\infty} \underset{\infty}{\infty} \underset{n}{\infty}$

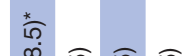

II

主

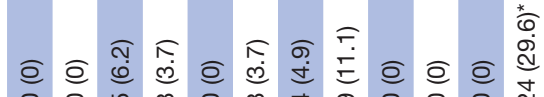

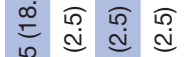

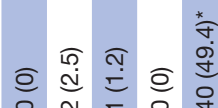

* $\widehat{\circ}$ б

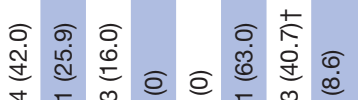

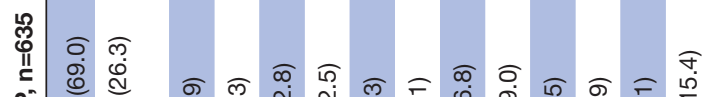

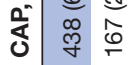

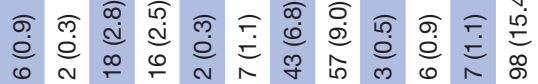

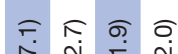

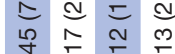

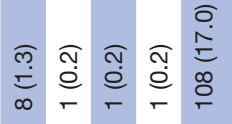

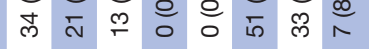

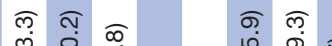

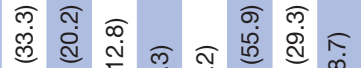

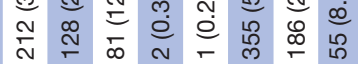
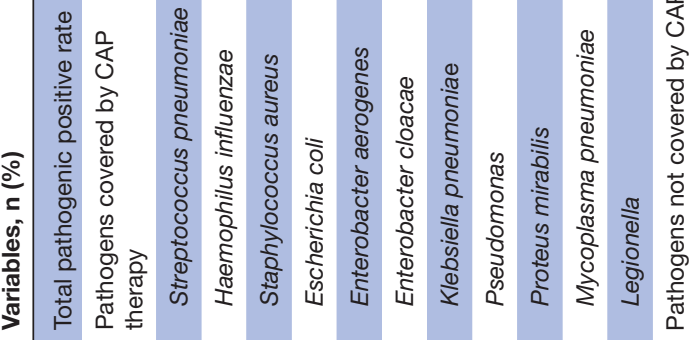

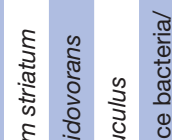

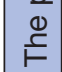

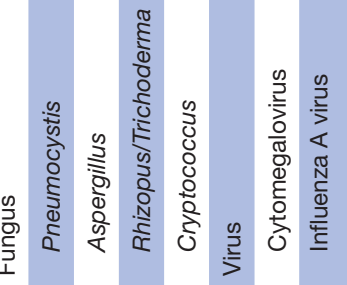




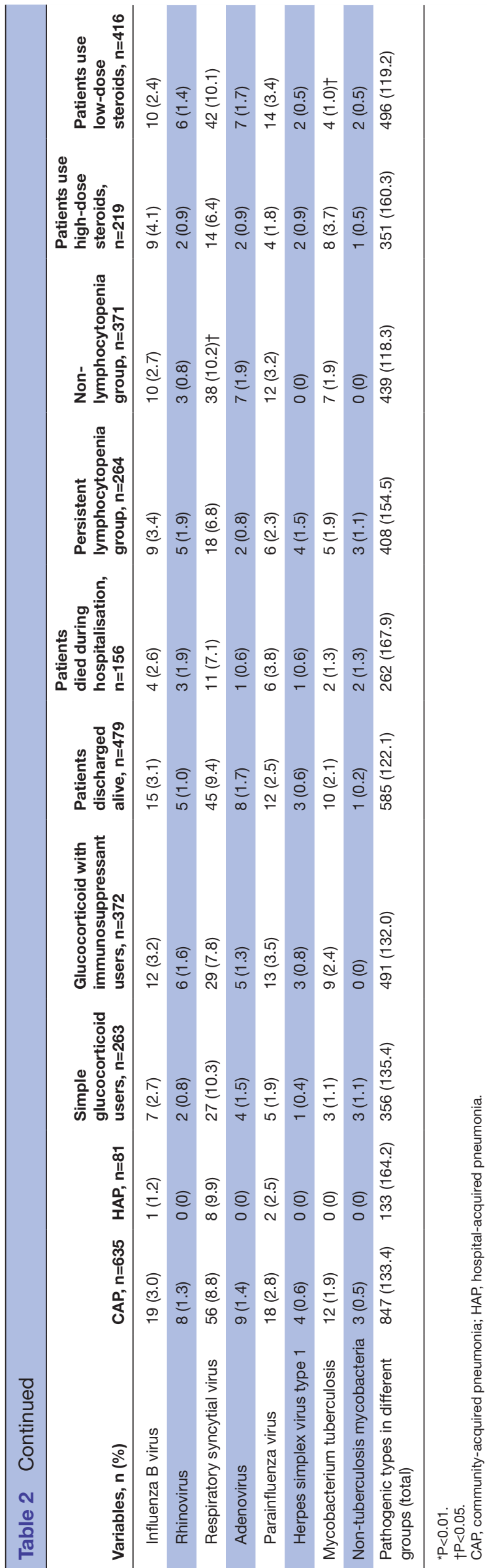

Pathogen positivity rates were higher, and MDR bacteria were more commonly identified in non-survivors than in survivors of CAPs or HAPs $(\mathrm{p}<0.05)$ (tables 2 and 3). For non-CMV viral pneumonias, respiratory syncytial virus (RSV, 64 strains) was detected most frequently, followed by influenza A virus (62 strains), human parainfluenza virus (20 strains), influenza B virus (20 strains), human rhinovirus (HRV, 8 strains), herpes simplex virus type 1 (4 strains) and adenovirus (9 strains) (table 2).

Patients with non-CMV viral pneumonias had higher $\mathrm{PaO}_{2} / \mathrm{FiO}_{2}$ ratios, lower rates of respiratory failure and lower 30-day and 90-day mortality than patients with PCP or CMV pneumonias $(\mathrm{p}<0.05)$ (table 4$)$. There were more PCP and CMV pneumonias in patients with nephrotic syndrome or chronic glomerulonephritis and more Aspergillus and non-CMV viral pneumonias in the solid organ transplant group; however, there were no statistically significant differences in mortality between patients with different underlying diseases (table 5).

Time analysis showed that $58.0 \%$ of patients developed pneumonia within 6 months of starting glucocorticoid therapy, with $74.0 \%$ of patients developing pneumonia within 1 year (figure 2). Of confirmed PCP cases, $79.0 \%$ developed pneumonia within 6 months of starting glucocorticoid therapy, with $86.0 \%$ developing pneumonia within 1 year. Of confirmed CMV pneumonia cases, $71.0 \%$ developed pneumonia within 6 months of starting glucocorticoid therapy, with $82.0 \%$ developing pneumonia within 1 year (figure 3). For non-CMV viral, Aspergillus and bacterial pneumonias, most patients developed pneumonia within 6 months of starting glucocorticoid therapy, though less frequently than in patients with CMV pneumonia or PCP (figure 2). The trends in the incidences of these pneumonia types were similar in patients treated with glucocorticoids and other immunosuppressants and in patients treated with glucocorticoids alone (figures 3 and 4).

Cox regression analysis indicated that the following factors were independent predictors of 30-day and 90-day mortality in patients with CAP treated with glucocorticoids and other immunosuppressants and in patients with CAP treated with glucocorticoids only: septic shock, respiratory failure and persistent lymphocytopenia. In the glucocorticoid-only group, high-dose corticosteroid use and invasive mechanical ventilation were independent negative predictors of 90-day mortality (table 6 ). Interstitial lung disease and mechanical ventilation were independent negative predictors of 90-day mortality in the glucocorticoid and immunosuppressant group (table 7).

\section{DISCUSSION}

This study was the first large-scale retrospective investigation of the aetiology and prognostic risk factors of pneumonia in patients using glucocorticoids. The main findings of the present study are summarised as follows: (1) more than $60 \%$ of patients developed pneumonia 


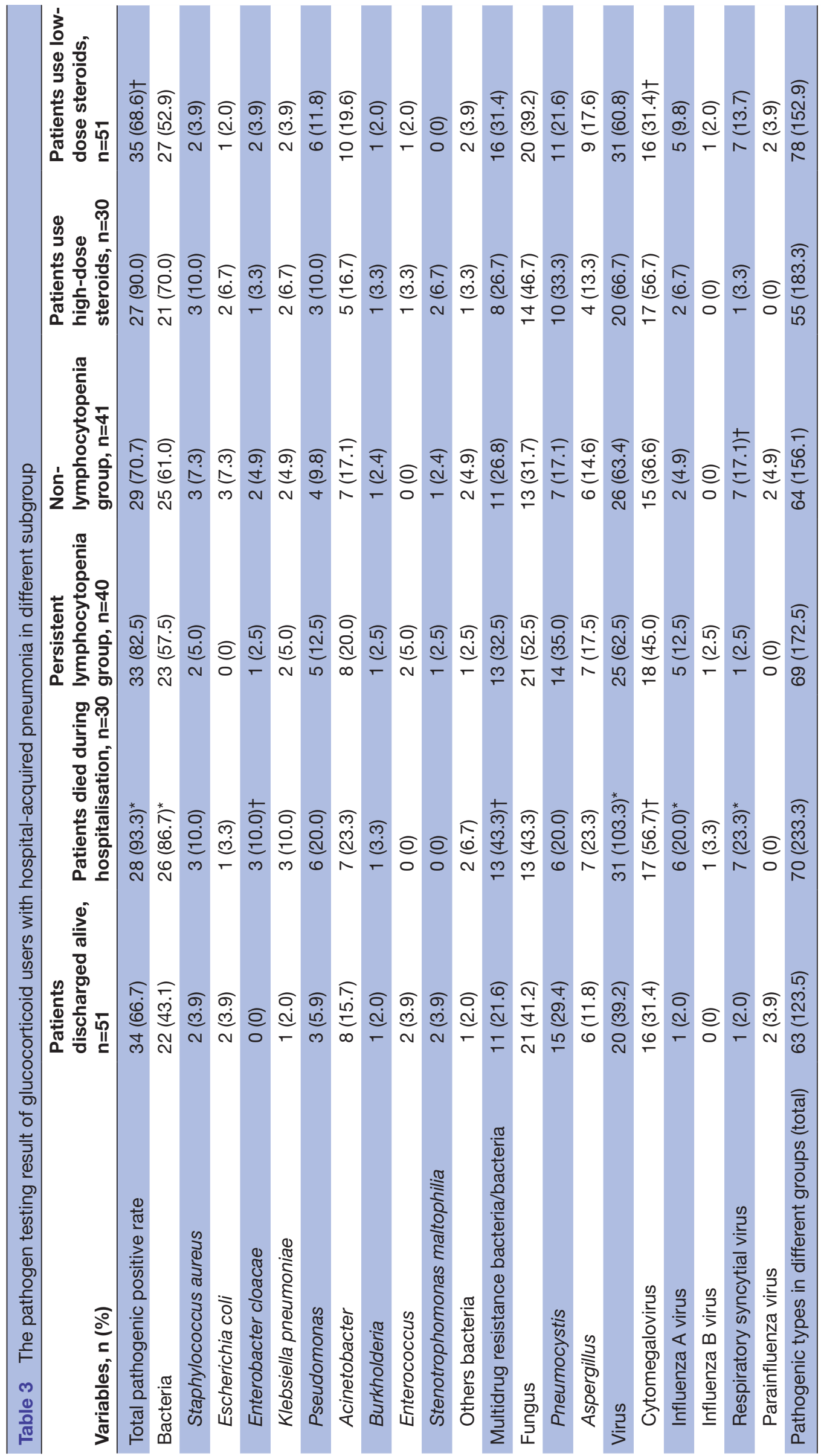


Table 4 Comparative analysis of Pneumocystis infection group and viral infection group

\begin{tabular}{|c|c|c|c|c|}
\hline Variables & $\begin{array}{l}\text { Pneumocystis } \\
\text { infection group, } \\
n=134\end{array}$ & $\begin{array}{l}\text { Non-CMV viral } \\
\text { infection group, } \\
n=157\end{array}$ & $\begin{array}{l}\text { CMV viral infection } \\
\text { group, } \\
\mathrm{n}=95\end{array}$ & $P$ value \\
\hline Sex, female, n (\%) & $65(48.5)$ & $56(35.7)$ & $32(33.7)$ & 0.033 \\
\hline Age, median (IQR) & $56.0(45.8,65.0)$ & $60.0(52.0,68.0)$ & $64.0(53.0,71.0)$ & $<0.001$ \\
\hline $\begin{array}{l}\text { Nephrotic syndrome or chronic } \\
\text { glomerulonephritis }\end{array}$ & $38(28.4)$ & $10(6.4)$ & $13(13.7)$ & $<0.001$ \\
\hline Solid organ transplant & $7(5.2)$ & $43(27.4)$ & $5(5.3)$ & $<0.001$ \\
\hline Connective tissue disease & $58(43.3)$ & $50(31.8)$ & $43(45.3)$ & 0.051 \\
\hline Interstitial lung disease & 49 (36.6) & $95(60.5)$ & $42(44.2)$ & $<0.001$ \\
\hline Idiopathic interstitial pneumonia & $12(9.0)$ & $28(17.8)$ & $14(14.7)$ & 0.091 \\
\hline \multicolumn{5}{|l|}{ Laboratory examination } \\
\hline White cell, $\times 10^{9} / L$ (IQR) & $8.22(5.50,11.46)$ & $8.45(5.94,11.59)$ & $7.96(5.77,12.65)$ & 0.888 \\
\hline Neutrophils, ×10\%/L (IQR) & $7.12(4.66,10.50)$ & $6.56(4.47,9.51)$ & $6.47(4.39,10.77)$ & 0.438 \\
\hline Lymphocyte, $\times 10^{9} / \mathrm{L}$ (IQR) & $0.60(0.40,1.00)$ & $0.99(0.60,1.55)$ & $0.91(0.49,1.57)$ & $<0.001$ \\
\hline Persistent lymphocytopenia & $74(55.2)$ & $62(39.5)$ & $39(41.1)$ & 0.017 \\
\hline Oxygenation index & $154.4(93.6,251.4)$ & $295.2(171.3,403.3)$ & $177.8(102.5,321.0)$ & $<0.001$ \\
\hline Severe pneumonia index score & $75.5(57.0,105.3)$ & $79.0(61.0,98.0)$ & $89.0(68.0,118.0)$ & 0.017 \\
\hline CURB-65 score $>1$ & $39(29.1)$ & $46(29.3)$ & $34(35.8)$ & 0.512 \\
\hline \multicolumn{5}{|l|}{ Imaging features, $\mathrm{n}(\%), 35$ missing } \\
\hline Consolidation or mass & $57(42.5)$ & $66(42.0)$ & $41(43.2)$ & 0.547 \\
\hline Ground-glass opacity & $102(76.1)$ & $83(52.9)$ & $51(53.7)$ & $<0.001$ \\
\hline \multicolumn{5}{|l|}{ Treatment, before admission, $\mathrm{n}(\%)$} \\
\hline High-dose steroids (>30 mg/day) & $73(54.5)$ & $39(24.8)$ & $41(43.2)$ & $<0.001$ \\
\hline $\begin{array}{l}\text { Accumulated dose of glucocorticoids, } \\
\text { methylprednisolone, g (IQR) }\end{array}$ & $3.3(2.2,5.8)$ & $2.9(1.2,6.8)$ & $4.0(2.1,7.4)$ & 0.186 \\
\hline Time of steroids use (month) & $3.0(2.0,5.0)$ & $5.0(2.0,16.0)$ & $4.0(2.0,12.0)$ & 0.291 \\
\hline Receiving other immunosuppressants & $58(43.3)$ & $67(42.7)$ & $45(47.4)$ & 0.749 \\
\hline \multicolumn{5}{|l|}{ Complications, n (\%) } \\
\hline Non-invasive ventilation & $51(38.1)$ & $29(18.5)$ & $29(30.5)$ & 0.001 \\
\hline Invasive mechanical ventilation & $41(30.6)$ & $43(27.4)$ & $27(28.4)$ & 0.831 \\
\hline Respiratory failure & $104(77.6)$ & $69(43.9)$ & $55(57.9)$ & $<0.001$ \\
\hline ICU care & $84(62.7)$ & $52(33.1)$ & $49(51.6)$ & $<0.001$ \\
\hline Septic shock & $38(28.4)$ & $40(25.5)$ & $22(23.2)$ & 0.667 \\
\hline Extracorporeal membrane oxygenation & $6(4.5)$ & $17(10.8)$ & $6(6.3)$ & 0.108 \\
\hline 30-day mortality & $45(33.6)$ & $32(20.4)$ & $23(24.2)$ & 0.034 \\
\hline 90-day mortality & $51(38.1)$ & 38 (24.2) & $26(27.4)$ & 0.030 \\
\hline
\end{tabular}

Non-CMV virus: respiratory syncytial virus (RSV), influenza A virus, influenza B virus, human parainfluenza virus (HPIV), human rhinovirus (HRV) and adenovirus.

CMV, Cytomegalovirus; CURB-65, Confusion, uremia, elevated respiratory rate, hypotension, and aged 65 years or older; ICU, intensive care unit.

within 6 months of glucocorticoid therapy initiation, especially for PCP and CMV pneumonias; (2) persistent lymphocytopenia was associated with significantly higher rates of infection by opportunistic pathogens, mixed pathogen types and MDR bacteria; (3) patients using high-dose glucocorticoids were significantly more likely to develop opportunistic pneumonias than those using low-dose glucocorticoids; (4) 30-day and 90-day mortality of patients with non-CMV and CMV viral pneumonias were similar, though lower than those with PCP; (5) septic shock, respiratory failure, mechanical ventilation, interstitial lung disease and persistent lymphocytopenia were independent predictors of 90-day mortality in patients receiving glucocorticoids. 


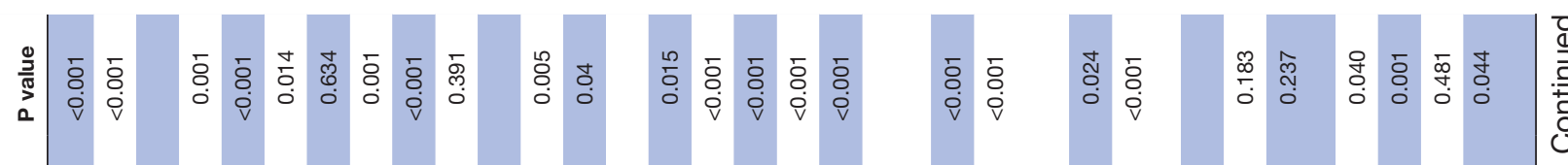

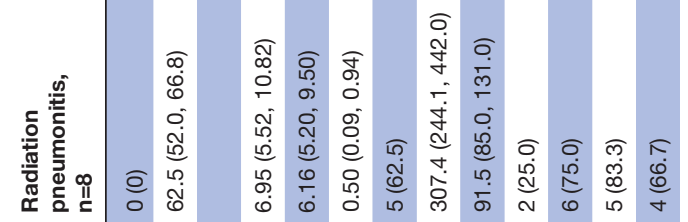

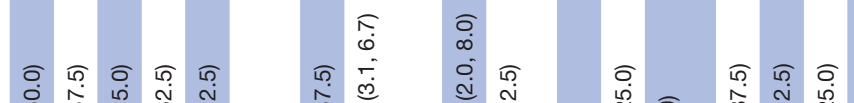

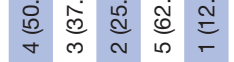
लू 垔

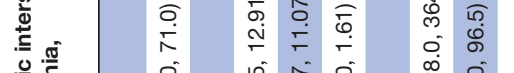

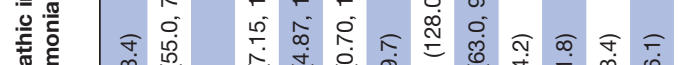

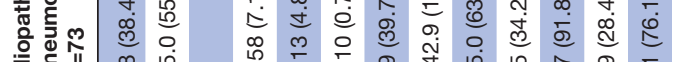

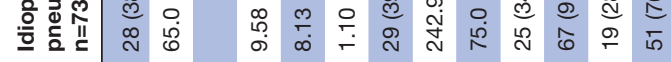

te t 6 te

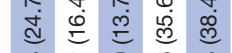
$\stackrel{\infty}{\sim} \underset{\sim}{\infty}$

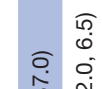

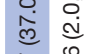

$\stackrel{\circ}{\underline{0}}$

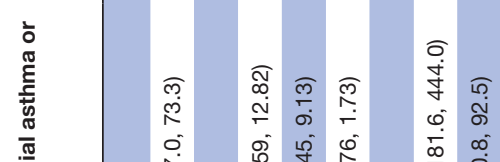

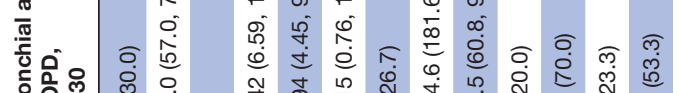

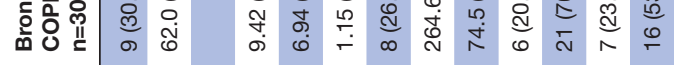

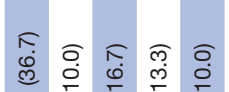
तิ

ำ

वृ लू

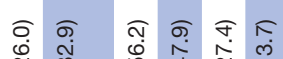

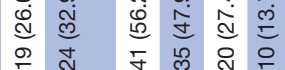

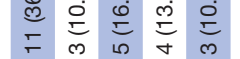

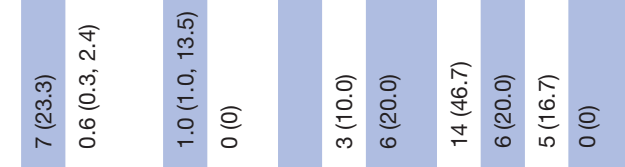

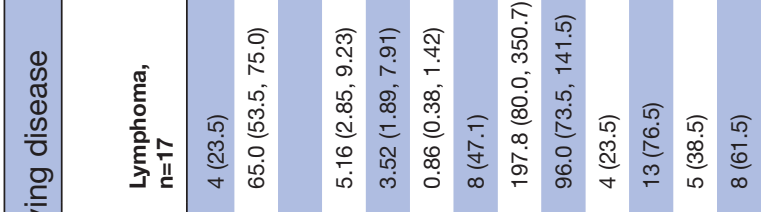

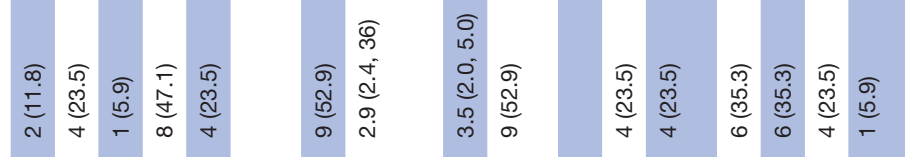

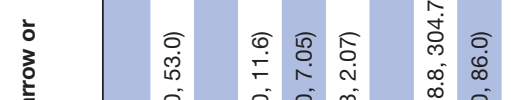

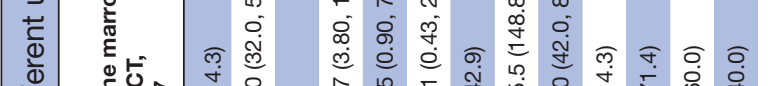

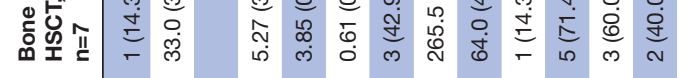

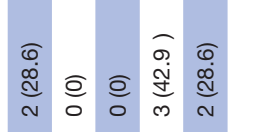

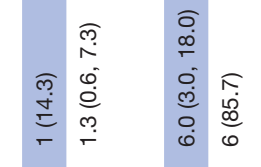

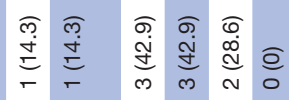

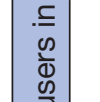

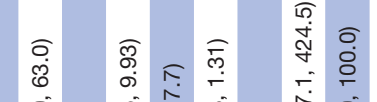

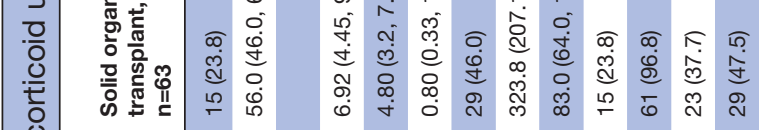

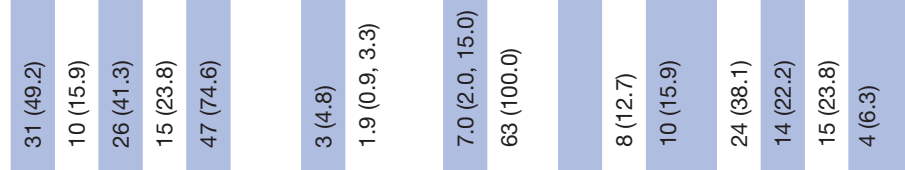

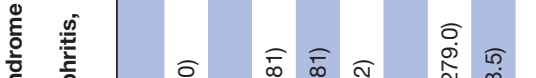

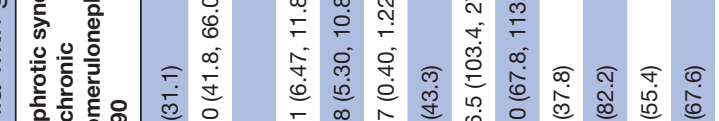

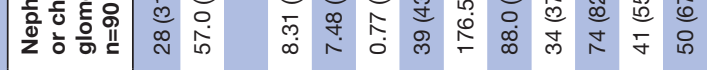

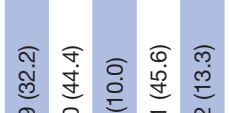

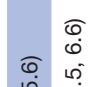

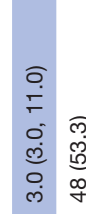

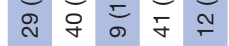

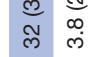

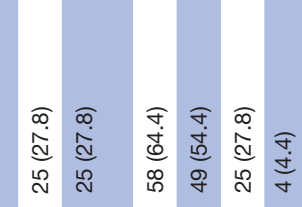

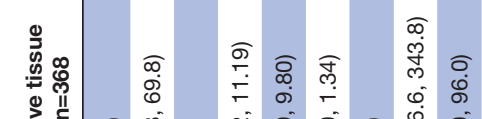

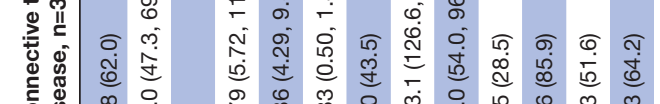

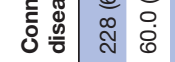

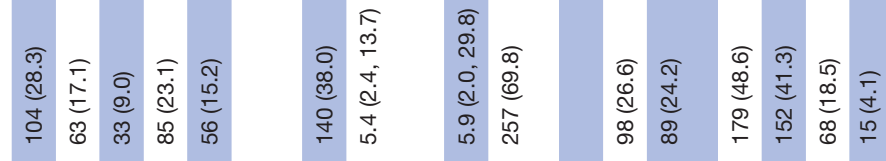

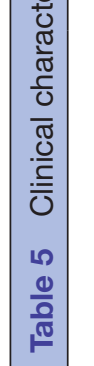
余

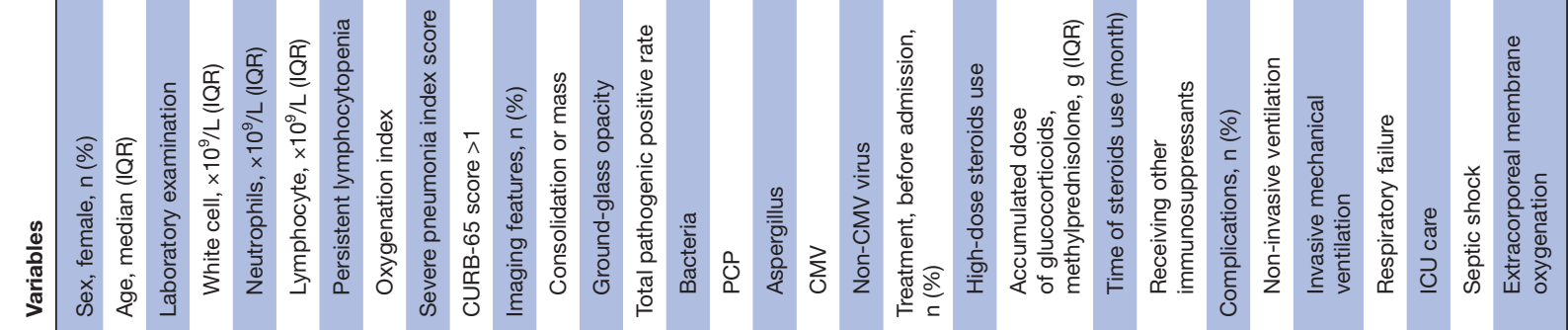

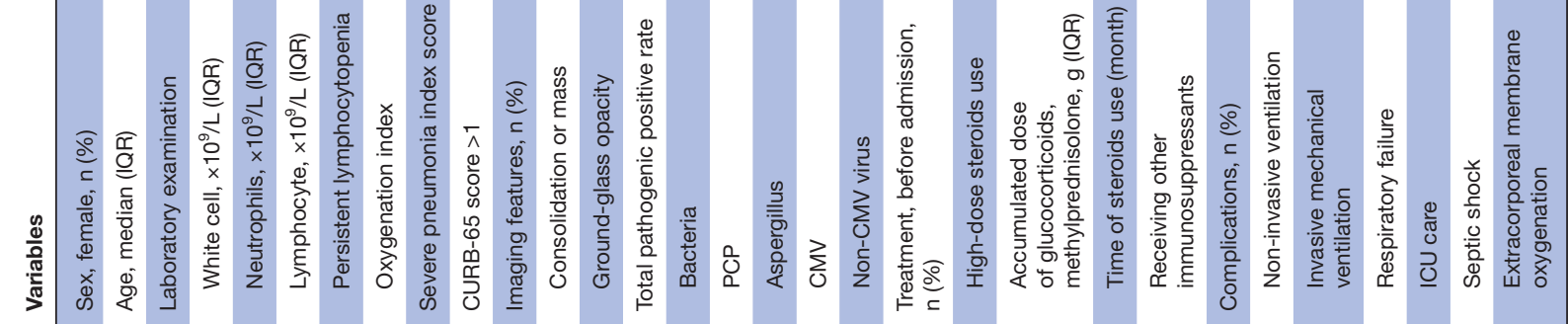

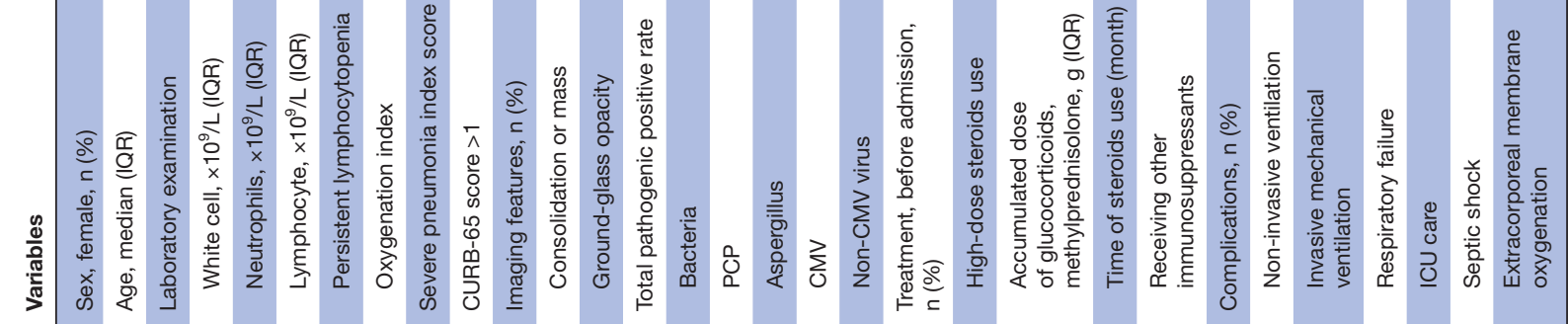



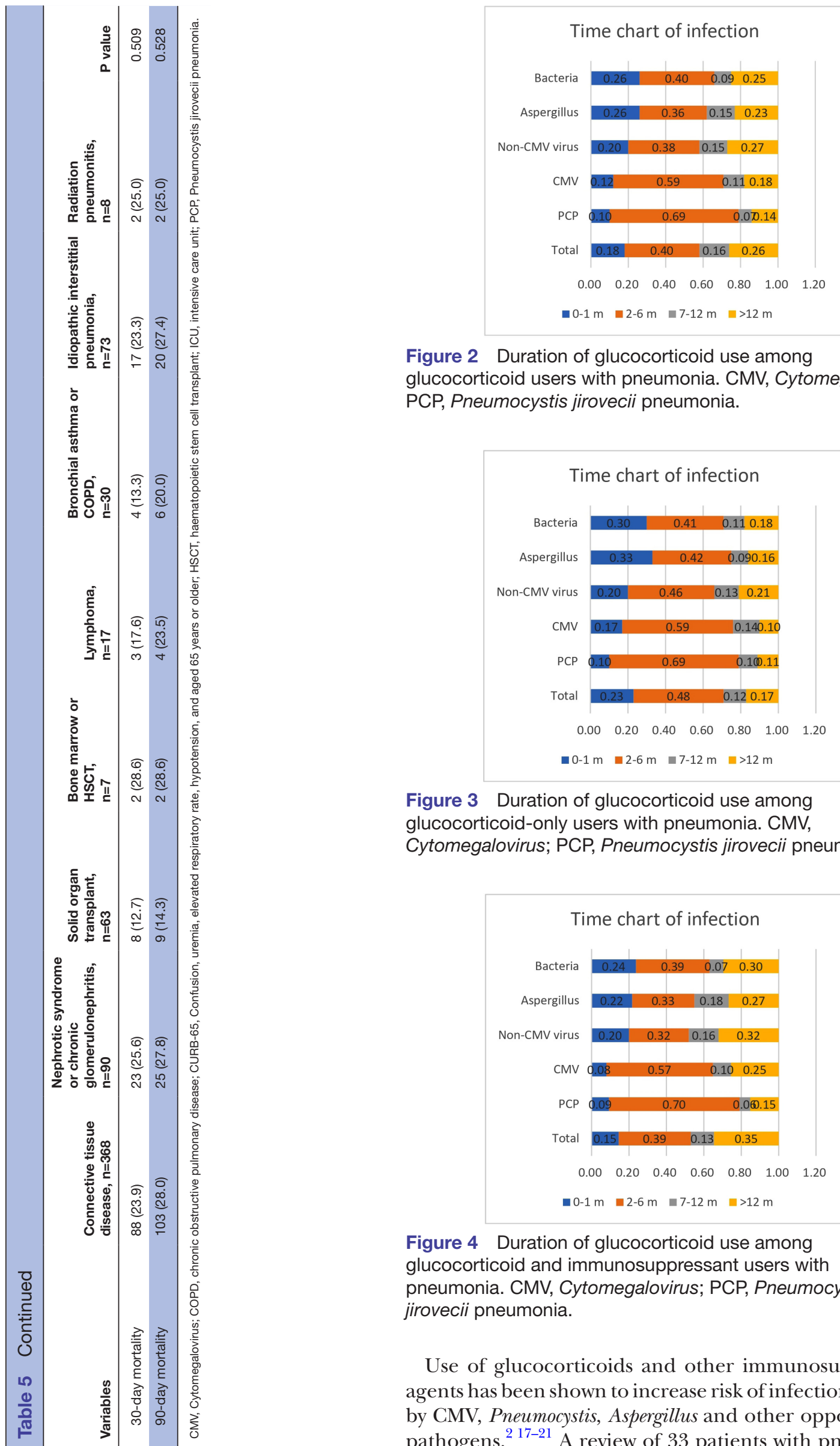

Figure 2 Duration of glucocorticoid use among glucocorticoid users with pneumonia. CMV, Cytomegalovirus; PCP, Pneumocystis jirovecii pneumonia.

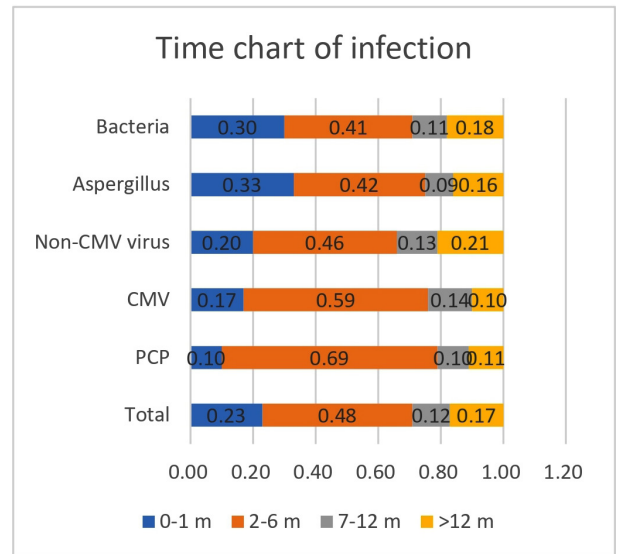

Figure 3 Duration of glucocorticoid use among glucocorticoid-only users with pneumonia. CMV, Cytomegalovirus; PCP, Pneumocystis jirovecii pneumonia.

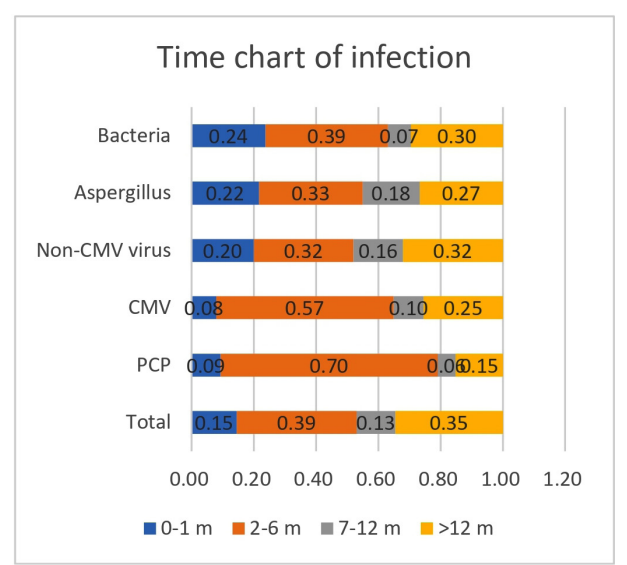

Figure 4 Duration of glucocorticoid use among glucocorticoid and immunosuppressant users with pneumonia. CMV, Cytomegalovirus; PCP, Pneumocystis jirovecii pneumonia.

Use of glucocorticoids and other immunosuppressive agents has been shown to increase risk of infections caused by CMV, Pneumocystis, Aspergillus and other opportunistic pathogens. ${ }^{217-21}$ A review of 33 patients with pneumonia 
Table 6 Cox regression analysis of prognostic factors in glucocorticoid users with community-acquired pneumonia

\begin{tabular}{|c|c|c|c|c|c|c|}
\hline \multirow[b]{2}{*}{ Variables } & \multicolumn{3}{|c|}{ 30-day mortality } & \multicolumn{3}{|c|}{ 90-day mortality } \\
\hline & OR & $95 \% \mathrm{Cl}$ & $P$ value & OR & $95 \% \mathrm{Cl}$ & $P$ value \\
\hline Septic shock & 5.874 & 3.210 to 10.750 & $<0.001$ & 4.9 & 2.685 to 8.941 & $<0.001$ \\
\hline Respiratory failure & 8.625 & 2.580 to 28.832 & $<0.001$ & 8.757 & 2.554 to 30.024 & 0.001 \\
\hline Persistent lymphocytopenia & 2.069 & 1.183 to 3.621 & 0.011 & 1.757 & 1.049 to 2.941 & 0.032 \\
\hline Invasive mechanical ventilation & - & - & - & 2.24 & 1.251 to 4.010 & 0.007 \\
\hline High-dose steroids & 1.989 & 1.145 to 3.456 & 0.015 & - & - & - \\
\hline
\end{tabular}

undergoing long-term glucocorticoid therapy showed that $S$. aureus was the most common pathogen identified, with a wide range of other causative pathogens, including bacteria, fungi, viruses, Pneumocystis and Mycobacterium. ${ }^{1}$ In an international multicentre study of immunocompromised patients, chronic steroid users accounted for $45 \%$ of patients, ${ }^{22}$ with the main causative pathogens for pneumonia including Streptococcus pneumoniae, P. aeruginosa, $K$. pneumoniae, S. aureus, influenza viruses and Pneumocystis. In our study, the most common pathogens isolated were bacteria, CMV, non-CMV viruses, Pneumocystis, Aspergillus or Cryptococcus, M. pneumoniae or Legionella, and M. tuberculosis or non-tuberculous mycobacteria. For bacterial pneumonias, $P$. aeruginosa, A. baumannii, $K$. pneumoniae and $S$. aureus were most commonly identified, possibly due to antibiotic therapy before admission. In some patients, BALs or sputum sampling occurred more than 48 hours after admission, increasing the risk of nosocomial aetiologies for pneumonia, including infection with A. baumannii.

An association between mixed pulmonary infections and treatment with glucocorticoids for nephrotic syndrome, lung transplantation or other disorders requiring immunosuppression has previously been reported. ${ }^{23-25}$ We found mixed infections in more than $50 \%$ of our study patients. Glucocorticoid use may also be a risk factor for MDR bacterial infections. We demonstrated that MDR bacterial infections were significantly more common in patients treated with high-dose steroids and in patients with persistent lymphocytopenia. Therefore, MDR pathogens must be considered when selecting antimicrobial agents for pneumonia in patients who are receiving high-dose steroids or in those with persistent lymphocytopenia.
A low CD4+ T-lymphocyte count has previously been shown to be associated with PCP. ${ }^{26}{ }^{27}$ Moreover, a low absolute lymphocyte count and prolonged high-dose steroid therapy have also been shown to be predictors of PCP and CMV infections. ${ }^{28-34}$ Yang et al demonstrated that the average time until diagnosis of PCP was only 2.4 months after immunosuppressant initiation in patients with glomerulonephritis. ${ }^{35}$ Our results underscore the importance of considering PCP in the differential diagnosis of patients receiving chronic high-dose glucocorticoids. This study also indicated that high-dose glucocorticoid use is associated with M. tuberculosis and Aspergillus pneumonias. It has been shown that glucocorticoids have profound effects on the distribution and function of immune cells, including a decrease in macrophage antifungal activity through inhibition of reactive oxidant intermediates and direct stimulation of growth of Aspergillus fumigatus. ${ }^{36}$

Respiratory viruses have also been recognised to be potential causes for pneumonia and death in immunocompromised individuals with haematological malignancies and those undergoing haematopoietic stem cell transplants. Jacobs et al found a 25\% overall 30-day mortality in 32 patients with haematological malignancies and HRV lower respiratory tract infections. ${ }^{37} \mathrm{~A}$ slightly higher mortality (27\%) was observed in a study by Shah et al of patients with lower respiratory tract infections caused by parainfluenza virus who were undergoing haematopoietic cell transplants or had haematological malignancies. ${ }^{38}$ Chatzis et al showed that $21.3 \%$ of an immunocompromised adult cohort with RSV pneumonia required ICU transfer, with nearly a $20 \%$ mortality.${ }^{39}$ Crotty et al conducted an observational cohort study of 284 patients with viral pneumonias, in which the majority $(51.8 \%)$ were immunocompromised, with a high overall in-hospital mortality $(23.2 \%){ }^{40}$

Table 7 Cox regression analysis of prognostic factors in glucocorticoid and immunosuppressant users with communityacquired pneumonia

\begin{tabular}{|c|c|c|c|c|c|c|}
\hline \multirow[b]{2}{*}{ Variables } & \multicolumn{3}{|c|}{ 30-day mortality } & \multicolumn{3}{|c|}{ 90-day mortality } \\
\hline & OR & $95 \% \mathrm{Cl}$ & P value & OR & $95 \% \mathrm{Cl}$ & $P$ value \\
\hline Septic shock & 4.438 & 2.783 to 7.077 & $<0.001$ & 4.03 & 2.549 to 6.370 & $<0.001$ \\
\hline Respiratory failure & 48.238 & 6.568 to 354.301 & $<0.001$ & 35.106 & 4.560 to 270.244 & 0.001 \\
\hline Persistent lymphocytopenia & 1.714 & 1.046 to 2.810 & 0.033 & 1.648 & 1.047 to 2.594 & 0.031 \\
\hline
\end{tabular}


In our study, the 90 -day mortality was $24.2 \%$ for patients with non-CMV viral pneumonias, which was similar to patients with CMV pneumonia (27.4\%), but significantly lower than patients with PCP $(38.1 \%, \mathrm{p}<0.05)$. Therefore, it is of vital importance to include viral pathogens in the differential diagnosis of pneumonia in patients on glucocorticoids. Also, the presence of ground-glass lesions on CT imaging should prompt consideration of PCP and viral infections. Viral nucleic acid and PCP testing should be obtained, and targeted antimicrobial treatment should be started as early as possible.

Overall mortality from pulmonary infections in patients receiving long-term glucocorticoid therapy can be as high as $45 \%,{ }^{1}$ with similar rates in patients with other causes for immunosuppression. ${ }^{19}$ Development of respiratory failure and the need for mechanical ventilation have been shown to be the strongest predictors of mortality in immunocompromised patients with or without pneumonia. ${ }^{412}$ Lymphocytopenia has also been shown to be significantly associated with increased mortality in non-HIV-infected patients with PCP or viral pneumonias. ${ }^{27}{ }^{43}$ Vial-Dupuy et al indicated that high-dose steroid use during an ICU stay ( $\mathrm{OR}=0.19 ; 95 \%$ CI 0.04 to 0.99$)$ was an independent determinant of in-hospital mortality in patients with interstitial lung disease admitted to the ICU. ${ }^{44}$ Kotani $e t a l$ s study indicated that interstitial lung disease was a risk factor associated with mortality in patients with PCP who required mechanical ventilation. ${ }^{45}$ Our study demonstrated that several factors conveyed a poor prognosis in this patient population, including high-dose glucocorticoid use, persistent lymphocytopenia and interstitial lung disease.

There were several limitations to this study. First, it had a retrospective observational design, which might have introduced some bias by indication. Second, not all patients with pneumonia underwent a full array of pathogenic testing; thus, pathogen identification and diagnosis may have been incomplete. Third, some pathogens were not identified until at least 48 hours after admission, increasing the possibility of nosocomial infections. Despite these limitations, our results are consistent with the existing literature and provide more detailed insights into the clinical characteristics, pathogenic aetiologies and prognostic factors that should be carefully considered when managing patients on glucocorticoid therapy who develop pneumonia.

\section{CONCLUSIONS}

Patients who develop pneumonia while receiving glucocorticoid therapy experience high rates of infection by opportunistic pathogens, significant morbidity and high mortality, especially with specific risk factors. This information should be carefully considered when determining treatment strategies for this patient population.

\section{Author affiliations}

${ }^{1}$ Department of Pulmonary and Critical Care Medicine, National Center for Clinical Research on Respiratory Diseases, China-Japan Friendship Hospital, Beijing, China
${ }^{2}$ Department of Medical Intensive Care Unit, Houston Methodist Hospital, Houston, Texas, USA

${ }^{3}$ Department of Pulmonary and Critical Care Medicine, First Hospital of Shijiazhuang, Shijiazhuang, China

${ }^{4}$ Department of Pulmonary and Critical Care Medicine, Second Hospital of Hebei Medical University, Shijiazhuang, Hebei, China

${ }^{5}$ Department of Respiratory and Critical Care Medicine, Beijing Luhe Hospital, Capital Medical University, Beijing, China

${ }^{6}$ Department of Pulmonary and Critical Care Medicine, Second People's Hospital of Weifang, Weifang, China

${ }^{7}$ Department of Pulmonary and Critical Care Medicine, Tianjin First Central Hospital, Tianjin, China

${ }^{8}$ Department of Pulmonary and Critical Care Medicine, Laboratory of Clinical Microbiology and Infectious Diseases; Institute of Respiratory Medicine, Chinese Academy of Medical Science; Tsinghua University-Peking University Joint Center for Life Sciences, China-Japan Friendship Hospital, Beijing, China

Twitter Lijuan Li @Li Lijuan

Contributors Study design: LL, CB. Data collection: LL, SJ, LSh, GS, LSu, LZ, CW, YR, JW, JP, JL. Statistical analysis: LL, SHH, XG. Writing: LL, CB, SHH. All authors take full responsibility for the study design, data analysis and interpretation, and preparation of the manuscript. All authors approved the final draft of the manuscript.

Funding This work was supported by the Ministry of Science and Technology Support Program (Grant: 2015BAl12B11) and the Beijing Science and Technology Commission Key Project (Grant: D151100002115004).

Competing interests None declared.

Patient and public involvement Patients and/or the public were not involved in the design, or conduct, or reporting, or dissemination plans of this research.

Patient consent for publication Parental/guardian consent obtained.

Ethics approval The Ethics Committee of China-Japan Friendship Hospital (No 2015-86) granted approval for this retrospective study and orchestrated centralised collaboration and approval of all participating institutions, including anonymised data submission and collection.

Provenance and peer review Not commissioned; externally peer reviewed.

Data availability statement Data are available in a public, open access repository. Extra data can be accessed via the Dryad data repository at https://datadryad.org/ stashe with the doi:10.5061/dryad.mkkwh70x2.

Open access This is an open access article distributed in accordance with the Creative Commons Attribution Non Commercial (CC BY-NC 4.0) license, which permits others to distribute, remix, adapt, build upon this work non-commercially, and license their derivative works on different terms, provided the original work is properly cited, appropriate credit is given, any changes made indicated, and the use is non-commercial. See: http://creativecommons.org/licenses/by-nc/4.0/.

ORCID iD

Lijuan Li http://orcid.org/0000-0001-5984-1603

\section{REFERENCES}

1 Agustí C, Rañó A, Filella X, et al. Pulmonary infiltrates in patients receiving long-term glucocorticoid treatment: etiology, prognostic factors, and associated inflammatory response. Chest 2003;123:488-98.

2 Ajmal S, Mahmood M, Abu Saleh O, et al. Invasive fungal infections associated with prior respiratory viral infections in immunocompromised hosts. Infection 2018;46:555-8.

3 Fillâtre P, Revest M, Belaz S, et al. [Pneumocystosis in nonHIV-infected immunocompromised patients]. Rev Med Interne 2016;37:327-36.

4 Kofteridis DP, Valachis A, Velegraki M, et al. Predisposing factors, clinical characteristics and outcome of Pneumonocystis jirovecii pneumonia in HIV-negative patients. $J$ Infect Chemother 2014;20:412-6.

5 American Thoracic Society, Infectious Diseases Society of America. Guidelines for the management of adults with hospital-acquired, ventilator-associated, and healthcare-associated pneumonia. Am J Respir Crit Care Med 2015;171:388-416. 
6 Sousa D, Justo I, Domínguez A, et al. Community-Acquired pneumonia in immunocompromised older patients: incidence, causative organisms and outcome. Clin Microbiol Infect 2013;19:187-92.

7 Jouneau S, Poineuf J-S, Minjolle S, et al. Which patients should be tested for viruses on bronchoalveolar lavage fluid? Eur J Clin Microbiol Infect Dis 2013;32:671-7.

8 Silva DR, Menegotto DM, Schulz LF, et al. Clinical characteristics and evolution of non-HIV-infected immunocompromised patients with an in-hospital diagnosis of tuberculosis. J Bras Pneumol 2010;36:475-84.

9 Marti C, Garin N, Grosgurin O, et al. Prediction of severe communityacquired pneumonia: a systematic review and meta-analysis. Crit Care 2012;16:R141.

10 Kwok CS, Loke YK, Woo K, et al. Risk prediction models for mortality in community-acquired pneumonia: a systematic review. Biomed Res Int 2013;2013:504136

11 Furtado GH, Wiskirchen DE, Kuti JL, et al. Performance of the PIRO score for predicting mortality in patients with ventilator-associated pneumonia. Anaesth Intensive Care 2012;40:285-91.

12 Aliberti S, Cilloniz C, Chalmers JD, et al. Multidrug-Resistant pathogens in hospitalised patients coming from the community with pneumonia: a European perspective. Thorax 2013;68:997-9.

13 Magiorakos A-P, Srinivasan A, Carey RB, et al. Multidrug-Resistant, extensively drug-resistant and pandrug-resistant bacteria: an international expert proposal for interim standard definitions for acquired resistance. Clin Microbiol Infect 2012;18:268-81.

14 Schauwvlieghe AFAD, Rijnders BJA, Philips N, et al. Invasive aspergillosis in patients admitted to the intensive care unit with severe influenza: a retrospective cohort study. Lancet Respir Med 2018:6:782-92.

15 Patterson TF, Thompson GR, Denning DW, et al. Practice guidelines for the diagnosis and management of aspergillosis: 2016 update by the infectious diseases Society of America. Clin Infect Dis 2016;63:e1-60.

16 Guo F, Chen Y, Yang S-L, et al. Pneumocystis pneumonia in HIV-infected and immunocompromised non-HIV infected patients: a retrospective study of two centers in China. PLoS One 2014:9:e101943.

17 Kim T, Park SY, Lee H-J, et al. Assessment of cytomegalovirus and cell-mediated immunity for predicting outcomes in non-HIVinfected patients with Pneumocystis jirovecii pneumonia. Medicine 2017;96:e7243.

18 Brownback KR, Pitts LR, Simpson SQ. Utility of galactomannan antigen detection in bronchoalveolar lavage fluid in immunocompromised patients. Mycoses 2013;56:552-8.

19 Rañó A, Agustí C, Jimenez P, et al. Pulmonary infiltrates in non-HIV immunocompromised patients: a diagnostic approach using noninvasive and bronchoscopic procedures. Thorax 2001;56:379-87.

20 Jolis R, Castella J, Puzo C, et al. Diagnostic value of protected BAL in diagnosing pulmonary infections in immunocompromised patients. Chest 1996;109:601-7.

21 Eyüboğlu F Ö, Küpeli E, Bozbas SS, et al. Evaluation of pulmonary infections in solid organ transplant patients: 12 years of experience. Transplant Proc 2013;45:3458-61.

22 Di Pasquale MF, Sotgiu G, Gramegna A, et al. Prevalence and etiology of community-acquired pneumonia in immunocompromised patients. Clin Infect Dis 2019;68:1482-93.

23 Popova VV, Shilov EM, Kornev BM, et al. [Development of mixed infection in patient with nephrotic syndrome on immunosuppressive therapy]. Ter Arkh 1998;70:56-7.

24 Qureshi S, Pandey A, Sirohi TR, et al. Mixed pulmonary infection in an immunocompromised patient: a rare case report. Indian $\mathrm{J}$ Med Microbiol 2014;32:79-81.

25 Hamadani M, Benson DM, Blum W, et al. Pulmonary Nocardia and Aspergillus co-infection in a patient with chronic graft-versus-host disease. Transplant Infect Dis 2008;10:24-6.
26 Williams KM, Ahn KW, Chen M, et al. The incidence, mortality and timing of Pneumocystis jiroveci pneumonia after hematopoietic cell transplantation: a CIBMTR analysis. Bone Marrow Transplant 2016:51:573-80.

27 Liu C-J, Lee T-F, Ruan S-Y, et al. Clinical characteristics, treatment outcomes, and prognostic factors of Pneumocystis pneumonia in non-HIV-infected patients. Infect Drug Resist 2019;12:1457-67.

28 Nierenberg NE, Poutsiaka DD, Chow JK, et al. Pretransplant lymphopenia is a novel prognostic factor in cytomegalovirus and noncytomegalovirus invasive infections after liver transplantation. Liver Transpl 2014:20:1497-507.

29 Werbel WA, Ison MG, Angarone MP, et al. Lymphopenia is associated with late onset Pneumocystis jirovecii pneumonia in solid organ transplantation. Transpl Infect Dis 2018;20:e12876.

30 Tadros S, Teichtahl AJ, Ciciriello S, et al. Pneumocystis jirovecii pneumonia in systemic autoimmune rheumatic disease: a casecontrol study. Semin Arthritis Rheum 2017;46:804-9.

31 Lee EH, Kim EY, Lee SH, et al. Risk factors and clinical characteristics of Pneumocystis jirovecii pneumonia in lung cancer. Sci Rep 2019;9:2094.

32 Lemiale V, Debrumetz A, Delannoy A, et al. Adjunctive steroid in HIVnegative patients with severe Pneumocystis pneumonia. Respir Res 2013;14:87

33 Tong J, Sun Z, Liu H, et al. Risk factors of CMV infection in patients after umbilical cord blood transplantation: a multicenter study in China. Chin J Cancer Res 2013;25:695-703.

34 Park JW, Curtis JR, Kim MJ, et al. Pneumocystis pneumonia in patients with rheumatic diseases receiving prolonged, non-highdose steroids-clinical implication of primary prophylaxis using trimethoprim-sulfamethoxazole. Arthritis Res Ther 2019;21:207.

35 Yang C-Y, Yang A-H, Yang W-C, et al. Risk factors for Pneumocystis jiroveci pneumonia in glomerulonephritis patients receiving immunosuppressants. Intern Med 2012;51:2869-75.

36 Philippe B, Ibrahim-Granet O, Prévost MC, et al. Killing of Aspergillus fumigatus by alveolar macrophages is mediated by reactive oxidant intermediates. Infect Immun 2003;71:3034-42.

37 Jacobs SE, Lamson DM, Soave R, et al. Clinical and molecular epidemiology of human rhinovirus infections in patients with hematologic malignancy. J Clin Virol 2015;71:51-8.

38 Shah DP, Shah PK, Azzi JM, et al. Parainfluenza virus infections in hematopoietic cell transplant recipients and hematologic malignancy patients: a systematic review. Cancer Lett 2016;370:358-64.

39 Chatzis O, Darbre S, Pasquier J, et al. Burden of severe RSV disease among immunocompromised children and adults: a 10 year retrospective study. BMC Infect Dis 2018;18:111

40 Crotty MP, Meyers S, Hampton N, et al. Epidemiology, co-infections, and outcomes of viral pneumonia in adults: an observational cohort study. Medicine 2015;94:e2332.

41 Rañó A, Agustí C, Benito N, et al. Prognostic factors of non-HIV immunocompromised patients with pulmonary infiltrates. Chest 2002;122:253-61.

42 Azoulay E, Pickkers P, Soares M, et al. Acute hypoxemic respiratory failure in immunocompromised patients: the Efraim multinational prospective cohort study. Intensive Care Med 2017:43:1808-19.

$43 \mathrm{Shi} \mathrm{SJ}$, Li H, Liu M, et al. Mortality prediction to hospitalized patients with influenza pneumonia: $\mathrm{PO} / \mathrm{FiO}$ combined lymphocyte count is the answer. Clin Respir J 2017;11:352-60.

44 Vial-Dupuy A, Sanchez O, Douvry B, et al. Outcome of patients with interstitial lung disease admitted to the intensive care unit. Sarcoidosis Vasc Diffuse Lung Dis 2013;30:134-42.

45 Kotani T, Katayama S, Miyazaki Y, et al. Risk Factors for the Mortality of Pneumocystis jirovecii Pneumonia in Non-HIV Patients Who Required Mechanical Ventilation: A Retrospective Case Series Study. Biomed Res Int 2017;2017:7452604 